\title{
CFD Analysis of an Innovative Wind Tower Design with Wind-Inducing Natural Ventilation Technique for Arid Climatic Conditions
}

\author{
Bushra Obeidat ${ }^{1 *}$, Hammam Kamal' ${ }^{1}$, Amal Almalkawi ${ }^{1}$ \\ 1 Department of Architecture, College of Architecture and Design, Jordan University of Science and Technology, \\ 3030, Irbid 22110, Jordan \\ * Corresponding author's e-mail: bbobeidat@just.edu.jo
}

\begin{abstract}
Wind towers are passive architectural elements traditionally used to ventilate buildings in the Middle East's hot and arid regions. Some recent design initiatives in Jordan are particularly interested in using passive systems for natural ventilation. This paper focuses on an innovative wind tower design as a passive ventilation system, which will be integrated into a train station design in Aqaba, Jordan to improve the air quality in indoor spaces and reduce the cooling loads. The design uses wind-induced effects as the motivating forces to improve natural ventilation. The study optimized the wind tower and evaluated its performance using Autodesk Computational Fluid Dynamics (CFD) simulations and Grasshopper Rhino plug-ins. Airflow and distribution through the tower were analyzed using the CFD model. Grasshopper definitions were used to examine the tower efficiency in lowering the indoor air temperature. Simulations indicated the potential of the proposed wind tower to reduce the temperature by $6.164^{\circ} \mathrm{C}$ and supply the interior space with the required fresh air rates. This article outlines how wind towers can be used in contemporary architecture and incorporate the simulation methods to pave the way for architects to effectively validate the performance of their design proposals at the early design stage.
\end{abstract}

Keywords: wind tower; computational fluid dynamics; natural ventilation; wind pressure fluctuations; indoor air quality; passive ventilation system.

\section{INTRODUCTION}

In the context of energy consumption, buildings are the main energy consumer worldwide. Statistics demonstrate that buildings consume approximately $50-60 \%$ of all produced energy in the world for heating, ventilation and air conditioning (HVAC) systems, and other demands (Jaber, 2002). Moreover, the buildings located in hot regions like Middle East rely heavily on energy to operate (HVAC) appliances to provide ventilation and thermal comfort which leads to an increase in the percentage of energy consumption by air conditioning compared to other climates. Moreover, the orientation towards designing buildings, without taking into account the passive design that reduces thermal loads and improves the human thermal comfort in indoor environments, would lead to energy and environment exhaustion (Alzoubi \& Malkawi, 2011; Omer, 2008).
Passive systems such as natural ventilation devices could achieve the energy efficiency needs and indoor environmental quality (Chenari, Carrilho, \& da Silva, 2016; Gil-Baez, Barrios-Padura, Molina-Huelva, \& Chacartegui, 2017; Papadopoulos \& Avgelis, 2003). Increasingly, they are being used in buildings to improve the fresh air quality and reduce the usage of mechanical (HVAC) systems (Chenari et al., 2016). Natural ventilation devices use the wind pressure and natural forces of the stack effect to aid and direct the air flow through buildings (Ghiaus \& Roulet, 2005). Wind pressure (or wind-induced natural ventilation) is based on wind pressure differences and the stack effect is created by temperature differences between the inside and outside spaces (Aynsley, 2014; Khan, $\mathrm{Su}, \&$ Riffat, 2008). There are various passive design responses which can be implemented to facilitate natural ventilation within buildings 
as windows, courtyards, chimney and exhaust cowls, wind catchers, and wind towers.

A wind tower or a wind catcher (Malqaf) is a vertical void inside a building and projected as an architectural element above the roof with openings oriented toward the prevailing wind (Billington \& Roberts, 1982). In the past, this device (called Malqaf, Barajeel, or Baudgeers) was used in many traditional buildings (Figure 1) in hot and arid climate regions such as Egypt, Jordan, Iran, and many parts of the Middle East to improve the natural air ventilation and cooling within the building (Badran, 2003; Bahadori, 1985; Kalantar, 2009). A wet cloth or water was used inside the device and work as an evaporative cooling system (Hughes, Calautit, \& Ghani, 2012). The wind towers are noted for their differing sizes and shapes and have traditionally been constructed from wood-reinforced masonry with openings (louvers) with heights of 2 to 20 meters above the building roof (Oliver, 1997). The taller towers capture wind at higher velocities and less dust (Ghadiri, Ibrahim, \& Dehnavi, 2011). Recently, wind towers have been used broadly in large public buildings with new and innovative designs such as those seen in the United Arab Emirates, in the case of wind towers in Master city and Barjeel Museum for Modern Arab Arts.

\section{Evaluation of wind towers efficiency}

A variety of studies have examined the efficiency of wind towers, the traditional and the modern designs, using computer simulations and experimental studies (Hughes et al., 2012). Studies showed that variations in the tower geometry such as the configuration of the capturing unit, the number of openings, tower height, internal tower width, evaporative cooling methods, and techniques of accelerating the inlet air (Calautit, Hughes, \& Sofotasiou, 2015; Ghadiri et al., 2011; Haw, Saadatian, Sulaiman, Mat, \& Sopian, 2012; Jomehzadeh et al., 2017; Montazeri \& Azizian, 2008; Montazeri \& Montazeri, 2018; Zaki, Richards, \& Sharma, 2019) could contribute to efficiency of the natural ventilation. These variations do not, however, adopt fixed rules, i.e. some configurations are suitable for certain regions or buildings, while for others they are totally impractical.

The research suggested that the curved or Venturi shapes of a wind catcher roof would create a pressure difference between the two sides of the roof (top and bottom) which contributes to the possibility of sucking the air from any opening on the tower (Haghighi, Golshaahi, \& Abdinejad, 2015; Lim, Saadatian, Sulaiman, Mat, \& Sopian, 2012) (as shown in Figure 2). The effects of the wind direction have also been investigated for different configurations of openings (Jomehzadeh et al., 2017; Montazeri, 2011). Most experiments demonstrated stronger output when the windward opening met the wind directly, i.e., zero degrees. A unidirectional tower has been recommended in the places where there is a prevailing wind (Calautit et al., 2015; Montazeri \& Azizian,

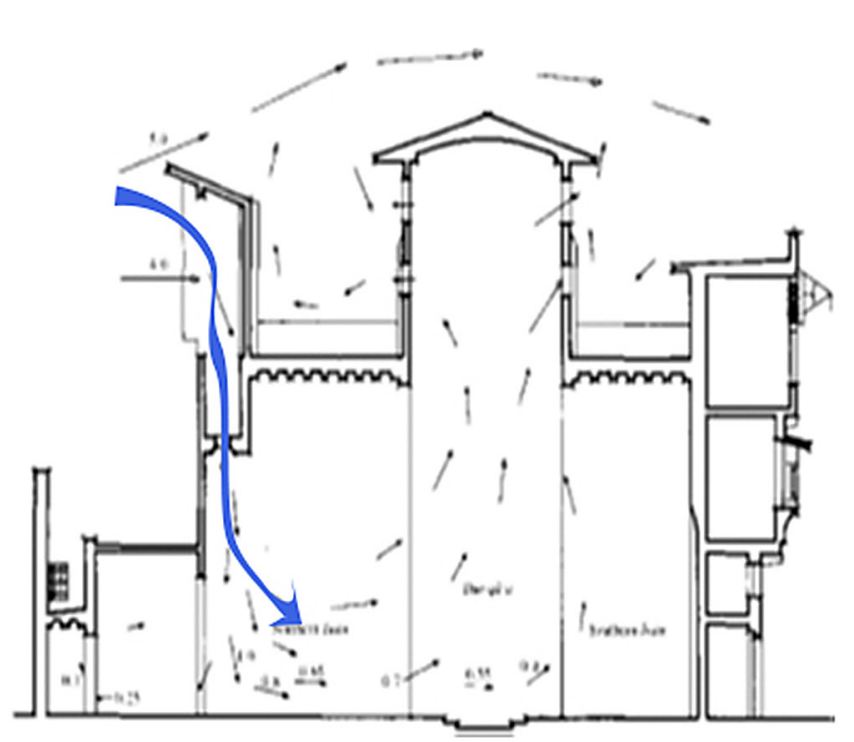

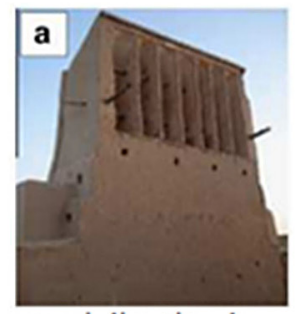

a. uni-directional

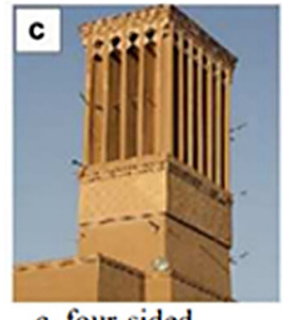

c. four-sided

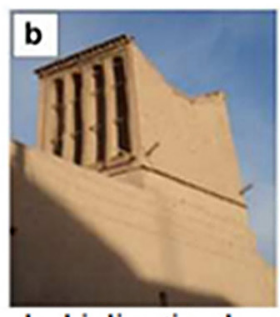

b. bi-directional

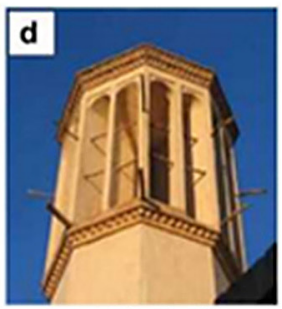

d. octahedral

Figure 1. A section through traditional wind tower (left) [Fathy (1986)]; different forms for Traditional towers (right) [Hughes et al. (2012)] 
2008). Studies found a significant effect of a curved configuration of the capturing unit (Figure 2) in increasing the airflow velocity, which leads to a good natural ventilation with minimum energy consumption (Pearlmutter, Erell, Etzion, Meir, \& Di, 1996).

Modern designs of wind towers are characterized by their great heights and control systems to reduce dust accumulation, reach levels of high air velocity, and maximize the amount of storage for cooling (Zaki et al., 2019). In order to improve their thermal efficiency, wind towers were equipped with evaporative cooling systems. In many wind tower systems, water was used as a heat sink in the evaporative cooling process to minimize air temperature and to humidify the interior environment (Jomehzadeh et al., 2017). The incorporation of heat transfer systems into conventional and modern wind catchers has also been evaluated as indirect cooling devices that reduce humidity relative to other evaporative cooling methods, making it feasible for humid areas (Calautit et al., 2015).

Most studies incorporated the CFD simulations and/or experimental studies to evaluate and optimize wind tower designs. Their work highlights the good correlation between the CFD predictions and the experimental results confirms the efficacy of computational analyses as a predictive method in this research area. The effectiveness of each ventilating system relies on he climatic conditions and the surrounding atmosphere to achieve human comfort in populated areas.

Due to its history and the use of multiple wind towers, most wind catcher studies were carried out in the Middle East, especially in Iran. Limited number of studies assessed the efficiency of wind towers in Jordan and considered its macroclimate conditions (Badran, 2003).

The purpose of this study was to optimize the design of a wind tower using computational fluid and thermal analyses. The proposed design was implemented using Aqaba, Jordan as the main study site. Thus, the study involved performance evaluations based on the climate information for the Aqaba region.

\section{The Study Site}

The study site was based in Aqaba, a coastal city in southern Jordan (Figure 3), which is located at $\left(31^{\circ} 12^{\prime} \mathrm{N} 36^{\circ} 30^{\prime} \mathrm{E}\right)$. Currently, the city of Aqaba is launching a major program of urban rehabilitation and sustainable development to improve the quality of life of residents, and to enhance the tourist and heritage value of the city (Abu-Ghazalah, 2008).

The redevelopment project includes creating links between the different parts of the city, such as the city center, the souk (traditional market), the old town, the fishing harbor, residential areas, and the cruise terminal. The Aqaba development program (ADP) therefore aims to improve the efficiency and comfort of public transport throughout the city, by developing many transportation hubs, train stations, and bus terminals, which will address the problems of congestion and pollution. The train station design in the ADP will be based on innovative design solutions that comply with environmental standards and energy savings. Compared with other large public buildings, railway stations have stringent requirements

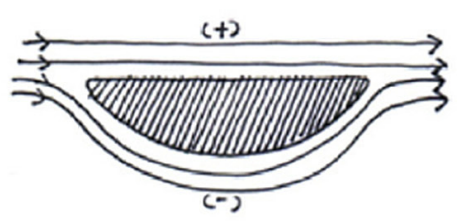

Venturi shaped roof profile with positive pressure above and negative pressure below

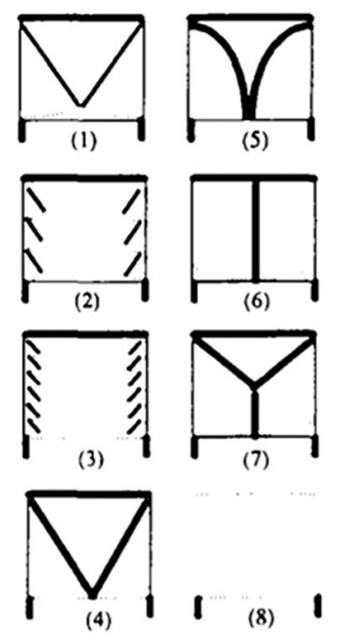

1

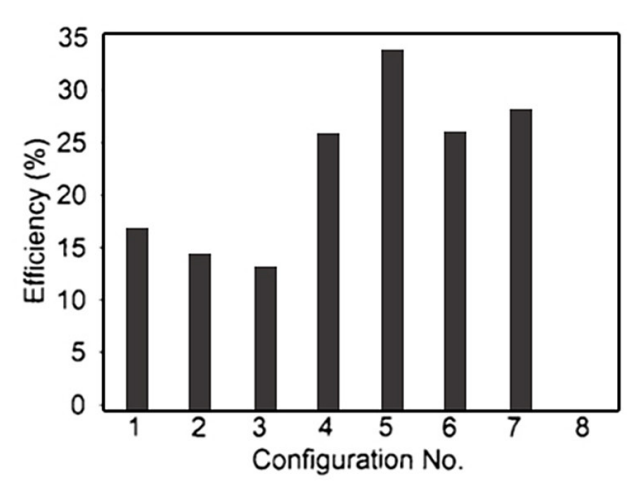

Figure 2. Various configurations of traditional wind towers -capturing unit [Pearlmutter et al. (1996)] 


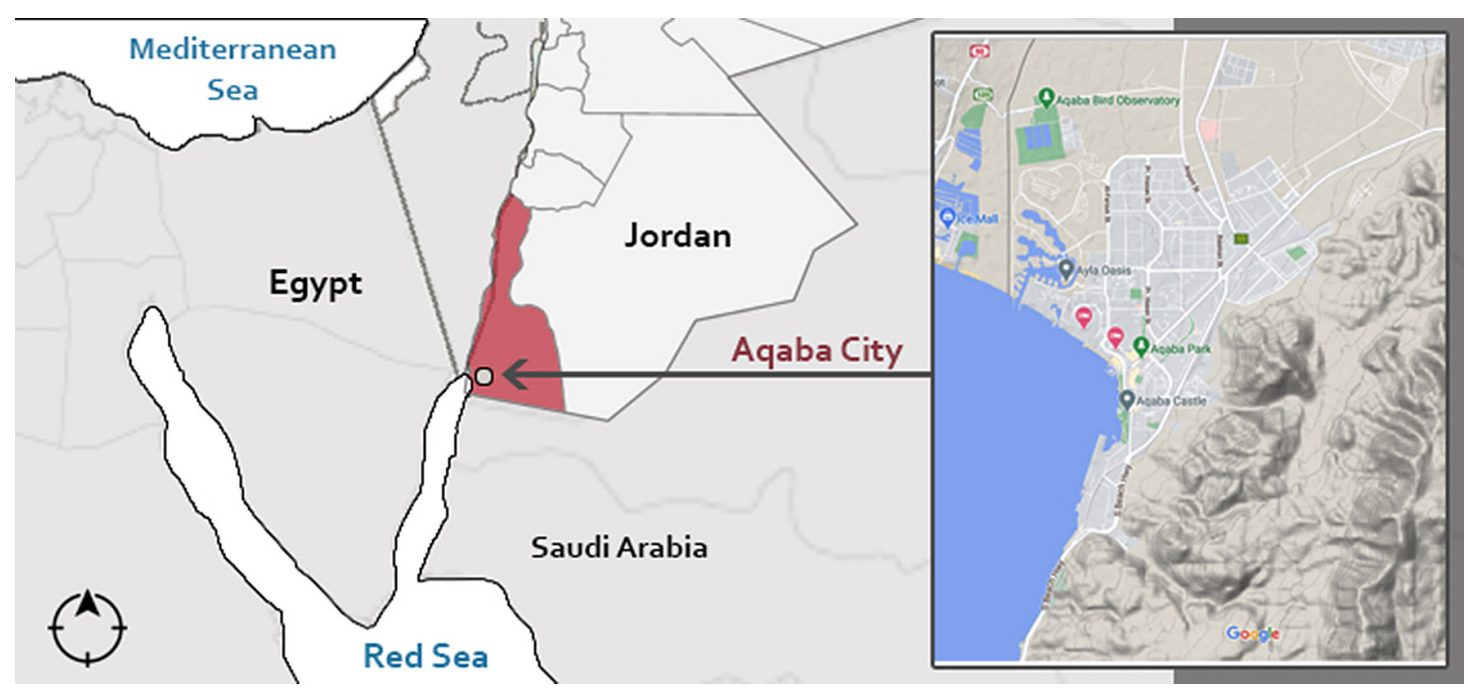

Figure 3. Map shows the location of Aqaba related to Jordan and surroundings

on the indoor air temperature, good ventilation, lighting, with comfortable indoor air temperature in waiting halls as a top priority. In order to provide good indoor air quality and ensure that no toxins are present in unhealthy quantities, the air at rail stations should be constantly extracted and replaced with fresh air from a clean, external source. Ventilation is very energy intensive; however, natural ventilation systems are gradually being used to cool train stations at lower energy costs (Yu et al., 2019).

In order to support our decision of choosing a passive cooling strategy, the Ladybug plugin in Grasshopper was used to generate a psychrometric chart to show the effectiveness of different passive strategies in the Aqaba region. The chart in Figure (4) indicates that $22.5 \%$ of the hours per year are in the comfort range. The best single passive design strategy is evaporative cooling which accounts for $38.65 \%$ of the hours. It has the advantage of being able to be combined with all the other cooling strategies.

The proposed geometry of the station consists of a roof covering the entire footprint of the plot (Figure 5). The authors decided to reinterpret the conventional form of wind tower and reshape it as a cooling device and a shelter. In this way, all indoor spaces benefit from the effects of the wind ventilation that is supported by a water evaporation technique inside the towers.

\section{METHODOLOGY}

In order to investigate the proposed design of a wind tower that is applied in the train station,

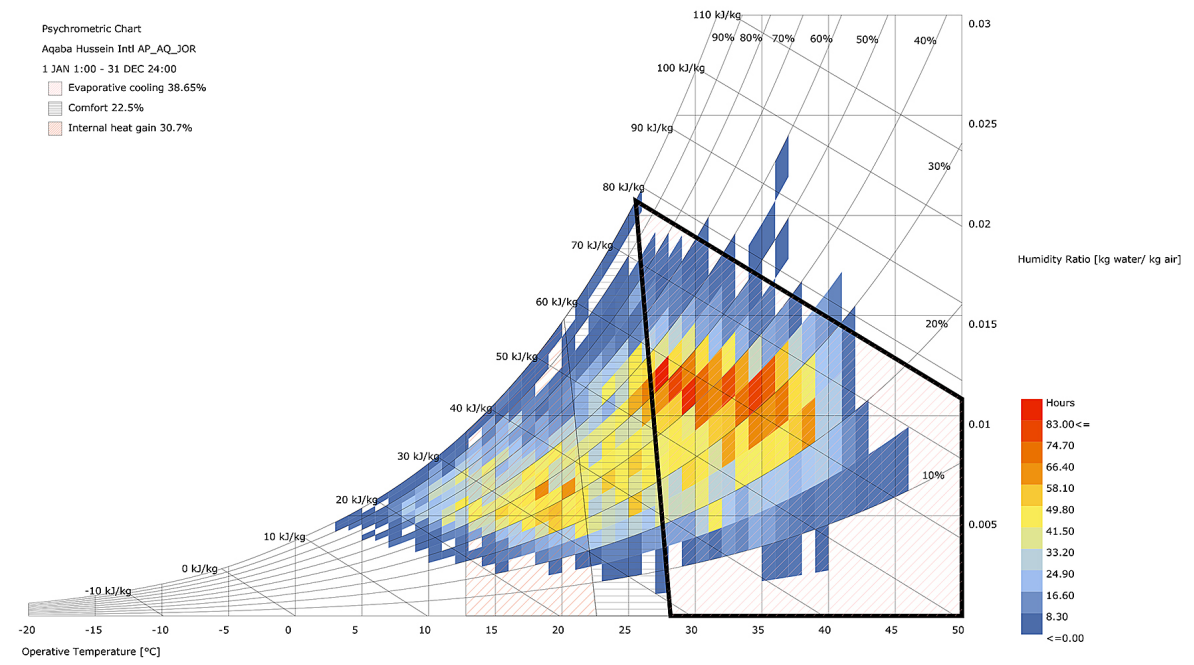

Figure 4. Psychrometric chart 

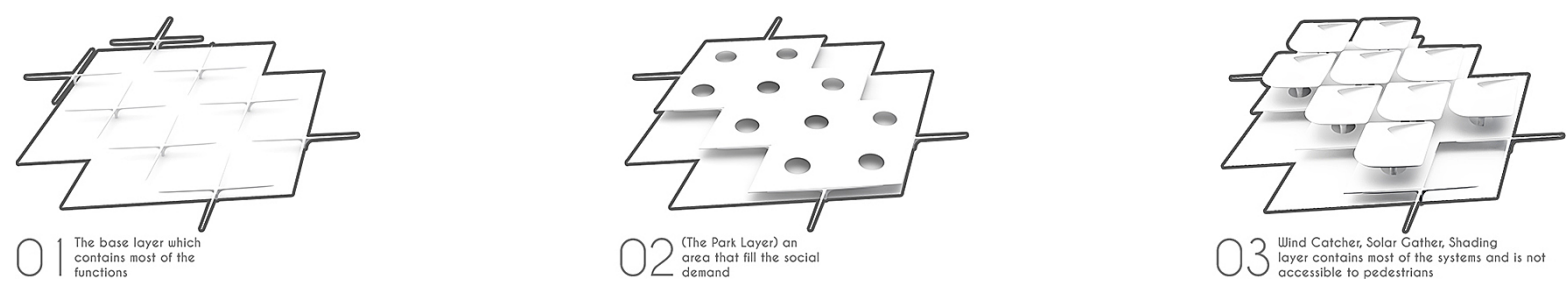

Figure 5. Train station design

two simulations were conducted: (1) wind analysis using Autodesk Computational Fluid Dynamics CFD to optimize the performance of the design in directing air into internal spaces, and (2) thermal study using Honeybee (energy plus) plugins for Grasshopper (Roudsari, Pak, $\&$ Smith, 2013) to examine the potential of the proposed device and minimize the indoor air temperatures.

\section{Geometry of the Wind Tower}

The experimental wind tower was created using Rhino 6 software (Figure 6). It consists of a capturing unit (upper air inlet), the main tower channel, evaporative cooling pad/cloth, and the lower air inlet. The total height of the experimental model is 17 meters.

\section{Wind Driven Simulations}

The CFD simulations evaluated the air flow around and through the wind tower to the interior spaces. The software was initially validated and calibrated by solving a simple example from Grondzik and Kwok (2019). This program has been tested by other studies calibrated against experimental wind tunnel data such as Li, Delmas, Donn, and Willis (2018) study.
The simulation study was carried out for a basic design of the experimental wind tower. In order to optimize the wind tower design and its performance in capturing the external wind directing it to the inside, several alterations have been developed by changing the shape of the capturing unit, the upper opening and the width of the main tower. Figure 7 shows the attempts to modify the design to reach out the final model.

The research assumed outdoor domain with dimensions as represented in Figure 8. The dimensions of the experimental wind tower and the indoor domain are clarified. This model was created using the Rhino software and then imported into Autodesk CFD to conduct the simulations. The total volume space of the outdoor domain is $1,117,600 \mathrm{~m}^{3}$. The model of the indoor domain has a window on the middle of one wall of the space with the dimension of $3 \times 3$ meters to allow the outlet air during the simulation. An evaluation plane is established through $t$ he mid-section of the space to view the airflow results.

\section{Wind Data}

The wind rose diagram (Figure 9a) from 1st March to 31st October, reveals that the prevailing wind is blowing from the North direction. The diagram indicates $5.87 \%$ of the days are

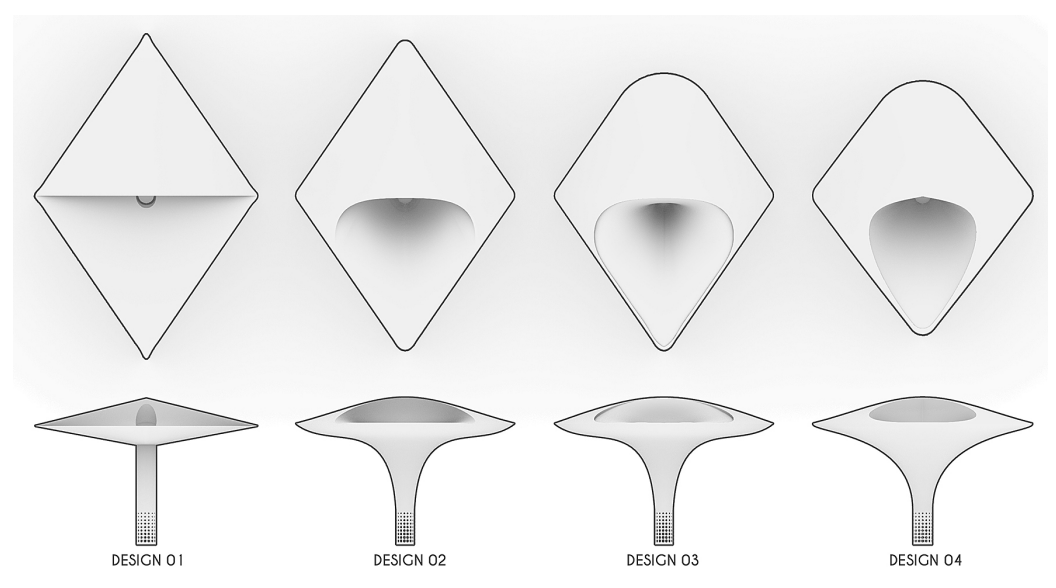

Figure 6. The details model of the experimental wind tower created by Rhino 


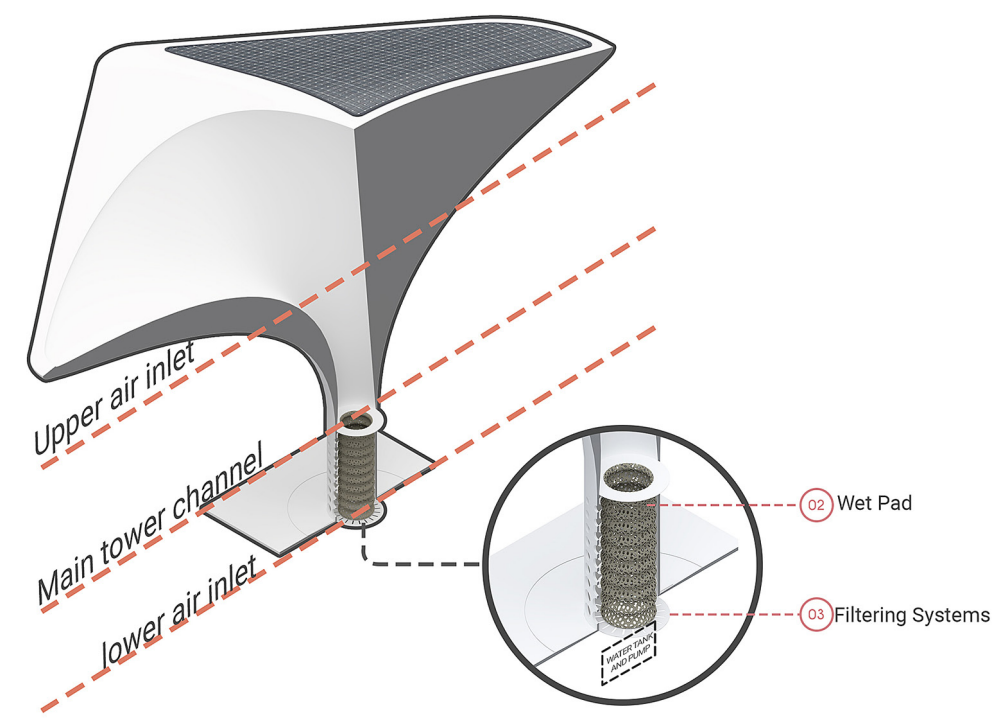

Figure 7. The design alternatives of the experimental wind tower

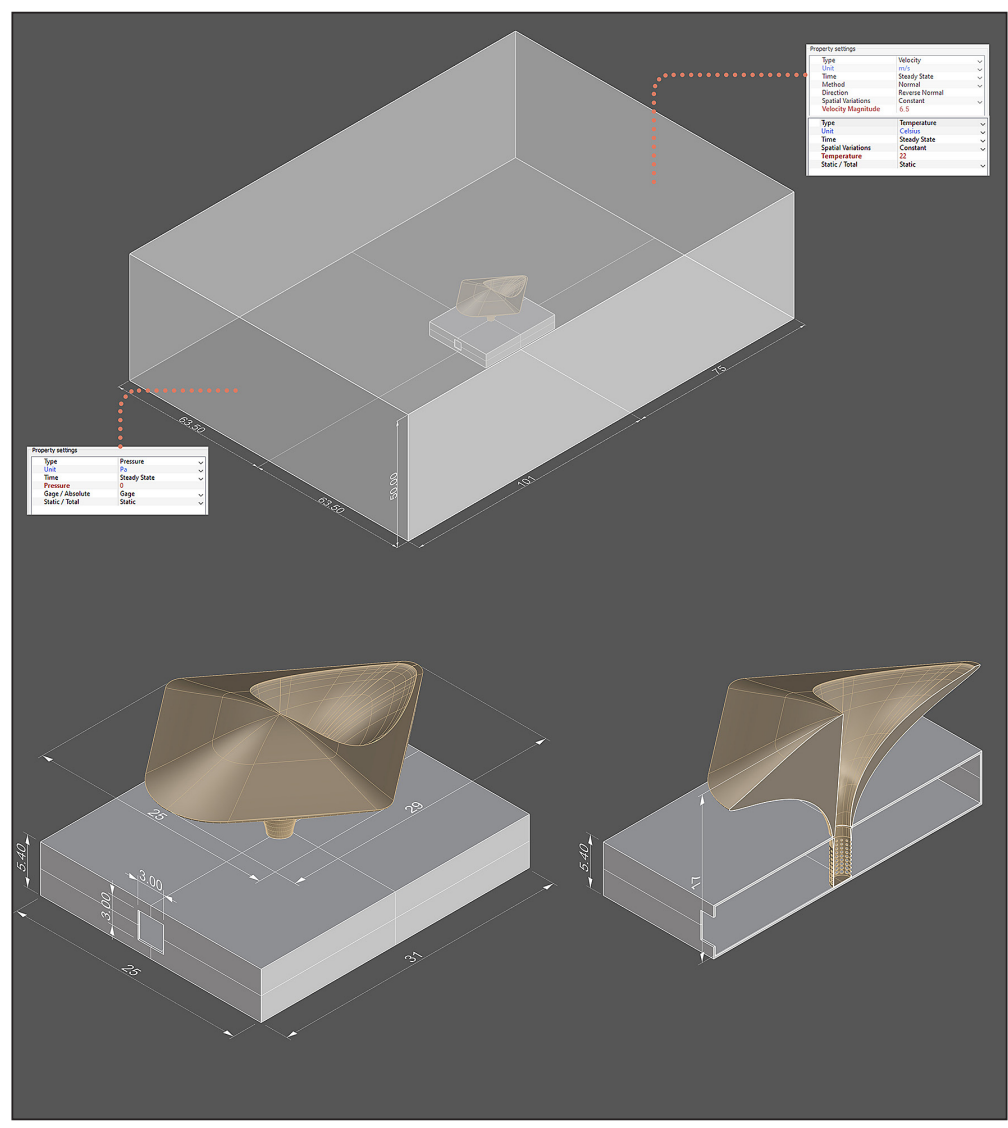

Figure 8. The outdoor domain around the experimental tower analyzed by CFD (top); the geometry of the experimental tower and the indoor domain analyzed by CFD (bottom)

calm days with air velocity less than $0.5 \mathrm{~m} / \mathrm{s}$, and more than $60 \%$ of the days have wind velocity ranging from $0.5 \mathrm{~m} / \mathrm{s}$ to $8.07 \mathrm{~m} / \mathrm{s}$. The orientation of the experimental wind tower is also seen in Figure (9a). The front façade and the main wind tower opening face the prevailing wind, which blows from the north. The equation of the Log Law Model is used to calculate the average wind velocity at a reference height of $17 \mathrm{~m}$ (Figure $9 \mathrm{~b}$ ). The mean wind speed is, thus, $6.5 \mathrm{~m} / \mathrm{s}$, which is used in the CFD model as a boundary condition. 

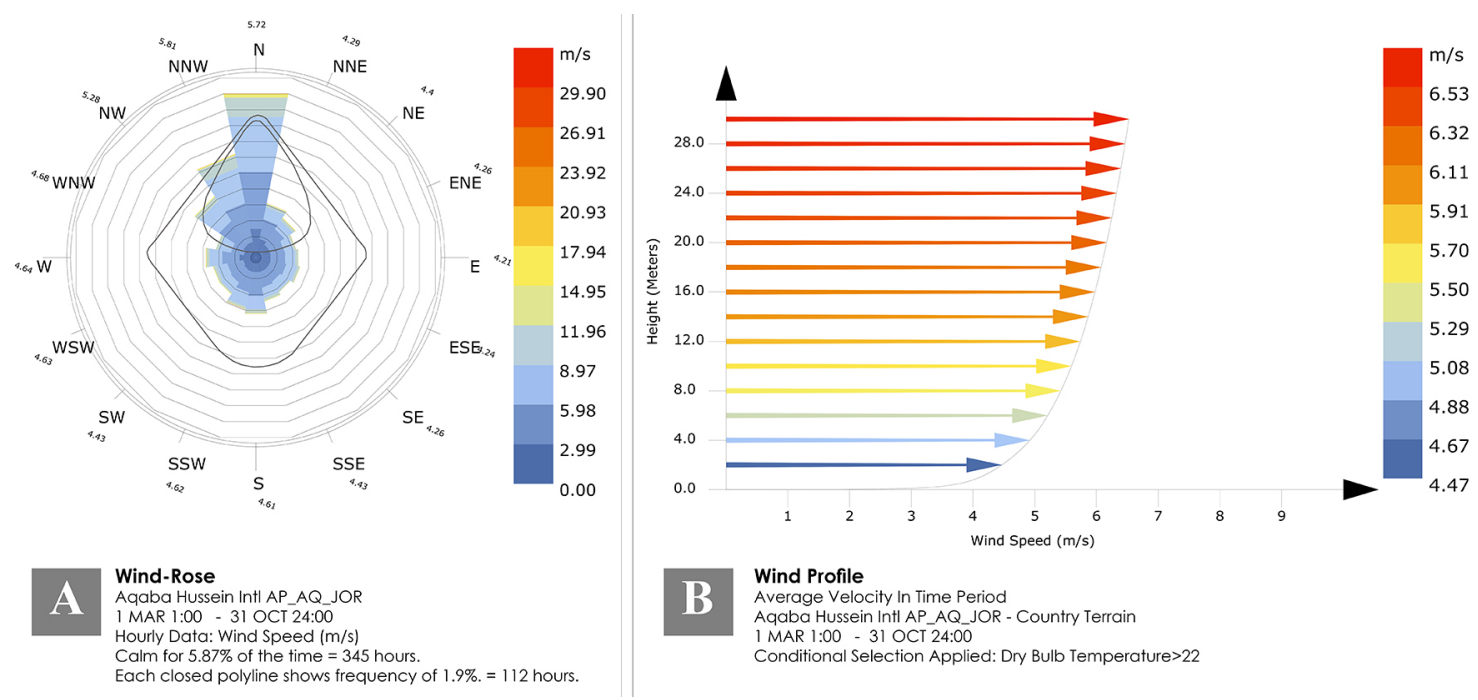

Figure 9. (A) Wind Rose of Aqaba (ladybug), (B) mean wind velocity at different heights

\section{Mesh Design and Sensitivity Analysis}

CFD provides an automated mesh generation process. This process is known as adaptive meshing, which refines the mesh based on iterative simulation results. This approach refines only some areas of the mesh by running the simulation numerous times, to settle on a stable and reliable solution. The initial coarse grid consisted of 960,676 elements and was refined over many run iterations (572 runs) until it reached convergence and an acceptable error of $0.01 \%$, which was achieved with a total of $3,867,377$ elements.

\section{Boundary Conditions}

The k-epsilon turbulence model with a static gage pressure $(p=0)$ is used for the simulation. The external ambient temperature was set at $22^{\circ} \mathrm{C}$. Table 1 below shows a summary of boundary conditions.

\section{Evaporative Cooling Study}

The evaporative cooling pad sits at the bottom of the wind tower (Figure 10). The air will pass through the wind tower channel and will be cooled by the wet pad. The computational simulations of the wind tower incorporating cooling device and its impact on the air temperature were conducted using a definition created in Rhino's Grasshopper, and use different components from Honeybee (energy plus) plugin for the environmental analysis. This tool was selected due to its graphical algorithm editing capabilities.
In order to use the grasshopper definition (Figure 10), the user is required to define the tower and interior domain geometry, the weather data for the study area, as well as the schedule and water flow rate. The definition then generates a chart for temperature for the tested period of time. The definition is initially calibrated by solving a simple example from Grondzik and Kwok (2019) in Grasshopper. A more rigorous calibration procedure is yet to be conducted.

\section{RESULTS}

\section{Airflow Analysis}

Figures (11-14) represent the simulation of air movement at different phases of the wind tower design optimization. The initial phase of optimization focused on the design of the capturing unit (upper part) to improve the air flow through the wind tower. The emphasis was placed on the passive design strategies without using fans or

Table 1. Summary of the CFD model boundary conditions

\begin{tabular}{|l|c|}
\hline \multicolumn{1}{|c|}{ Time } & Steady state \\
\hline Method & Normal \\
\hline Turbulence model & k-epsilon \\
\hline Velocity inlet $(\mathrm{m} / \mathrm{s})$ & $6.5 \mathrm{~m} / \mathrm{s}$ \\
\hline Pressure outlet & Static, gage, value $=0$ \\
\hline Gravity vector & Earth \\
\hline Temperature $\left({ }^{\circ} \mathrm{C}\right)$ & 22.0 \\
\hline
\end{tabular}




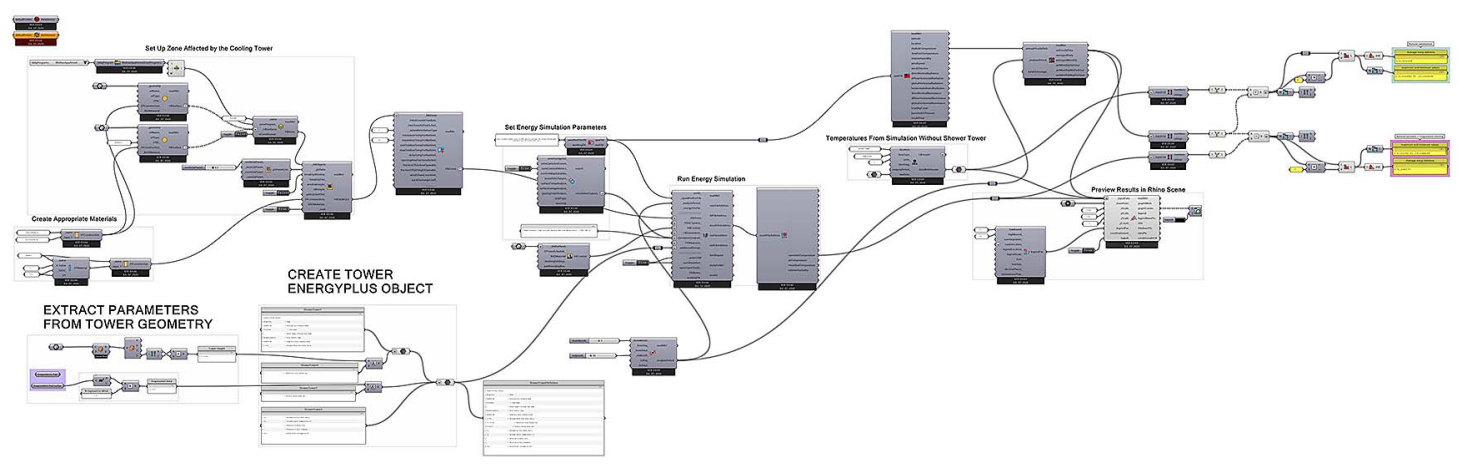

Figure 10. The evaporative cooling tower definition

Grasshopper definition: http://hydrashare.github.io/hydra/viewer?owner=chriswmackey\& fork=hydra_2\&id=Evaporative_Cooling_Tower\&slide $=0 \&$ scale $=1 \&$ offset $=0,0$

any mechanical tool to accelerate air. The simulations were carried out with wind speeds at $6.5 \mathrm{~m} / \mathrm{s}$ and ambient temperature $22^{\circ} \mathrm{C}$.

The basic design consists of a polygonal form for the top of upper unit, the front area facing the wind is narrow, then the shape expands to obtain quantities of air with a large opening. The CFD simulations (Figure 11a) demonstrated the failure of this design to deliver air to internal spaces. As the wind level at the lower parts of the tower reached a velocity below $1 \mathrm{~m} / \mathrm{s}$.

In the second alternative of the design (Figure $11 \mathrm{~b}$ ), the exterior of the top edges were smoothed to allow easier wind passage, and the tower opening was widened to receive more wind.
Simulations showed a small change in the internal wind speed, hitting a velocity from $1.7-2 \mathrm{~m} / \mathrm{s}$

In the third alternative, the upper aperture of the tower was reduced in diameter to improve the efficiency of the tower in terms of air suction into the interior. The modification has helped promote the introduction of air into the interior spaces. Wind velocity was $2-2.7 \mathrm{~m} / \mathrm{s}$ (Figure 11c).

The final optimization alternative was achieved by reducing the top size and volume, and designing the tower's inner cavity to be more streamlined. Such changes helped to improve the wind movement, which reached $3.5 \mathrm{~m} / \mathrm{s}$ at the lower parts of the tower. As clarified in Figure 11d the design also helped to establish variations in air
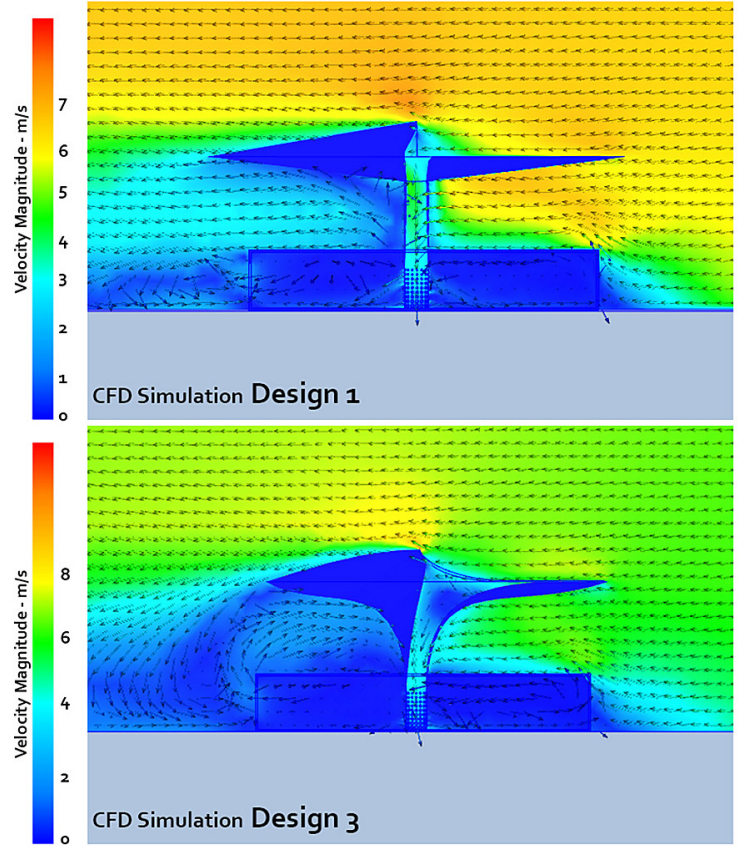
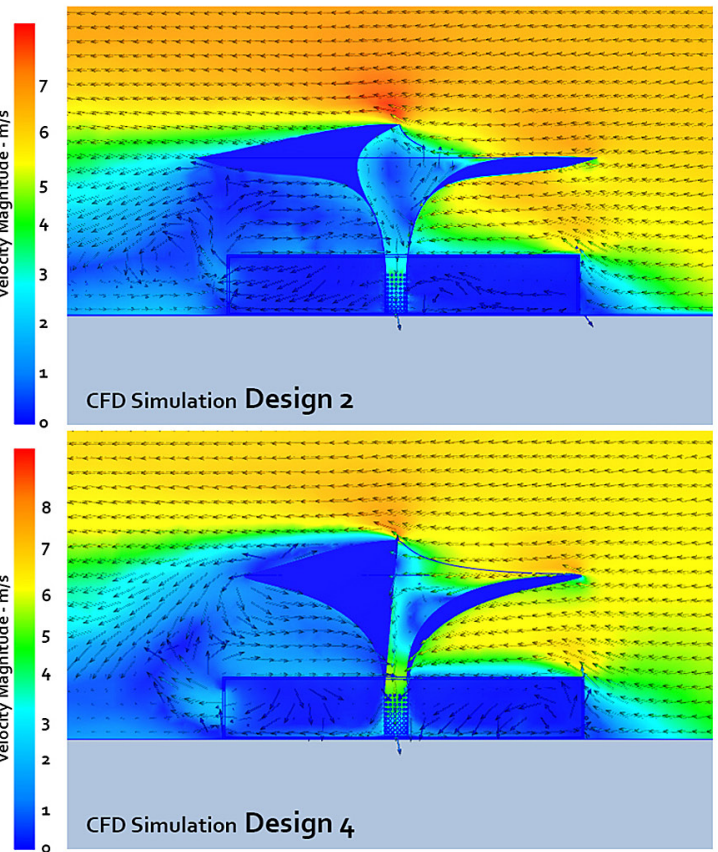

Figure 11. Airflow simulations for different stages of optimization 


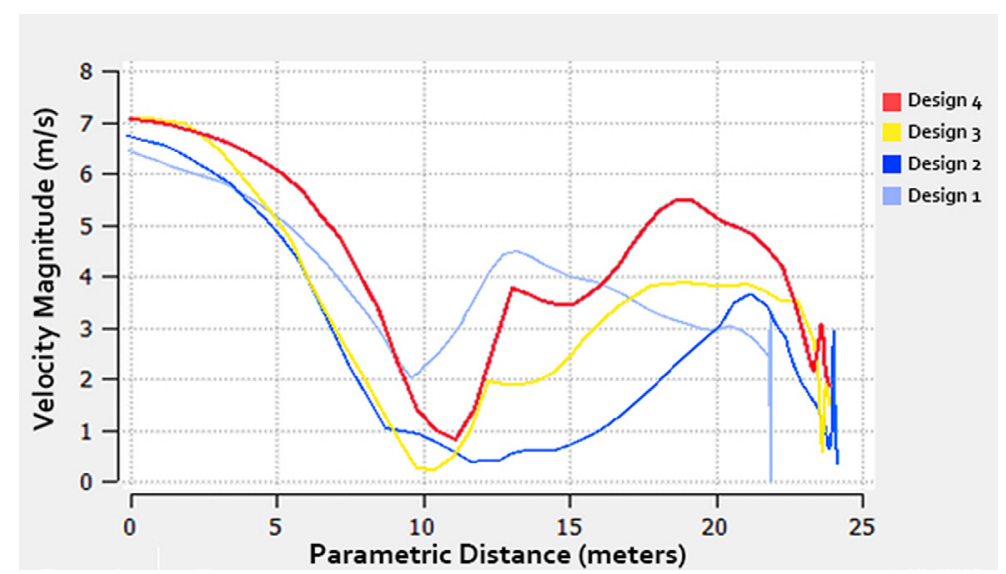

Figure 12. Air velocity values at different locations in the simulated designs

pressure between the front and rear of the tower, forcing air to flow through the windward opening of the tower into the low-pressure interior of the experimental room.

Simulations indicated (Figure 12) that the optimized design is capable of facilitating the air movement naturally, such that there is no significant difference between the wind speed at the top of the tower and the wind speed in the lower parts. The design can feed inner spaces with natural air, taking into account the height of the tower, which is $17 \mathrm{~m}$ high.

\section{Tower efficiency in Air Changes and Extraction}

The ventilation quality in buildings can be expressed by the air changes per hour $(\mathrm{ACH})$ values (Jiang et al., 2011). ACH is a metric that expresses how many times in an hour a device can fill and renew a full volume of a room or building with the fresh outdoor air (Sherman, 2004). Higher values correspond to better ventilation and optimal indoor air quality for building occupants. The air exchange rate is calculated from the equation:

$$
\mathrm{N}=\mathrm{Q} / \mathrm{V}
$$

where: $N=$ Number of air changes per hour

$Q=$ Volumetric flow rate $(\mathrm{cfm})$

$V=$ Room volume (cubic feet)

On the basis of the calculation, using the windinduced natural ventilation tower, the experimental tower managed to generate $11.355 \mathrm{ACH}$. This amount exceeds the minimum criteria set out in ASHRAE Standard 62 ventilation for transportation waiting area including, ticket\& baggage areas, corridors \& gale areas, platforms, concourses. ASHRAE requires an air exchange rate equal to 7.5 for these spaces (Drees, Wenger, \& Janu, 1992).

Figure 13 indicates the connection between the exterior velocity of the wind and the rate of air

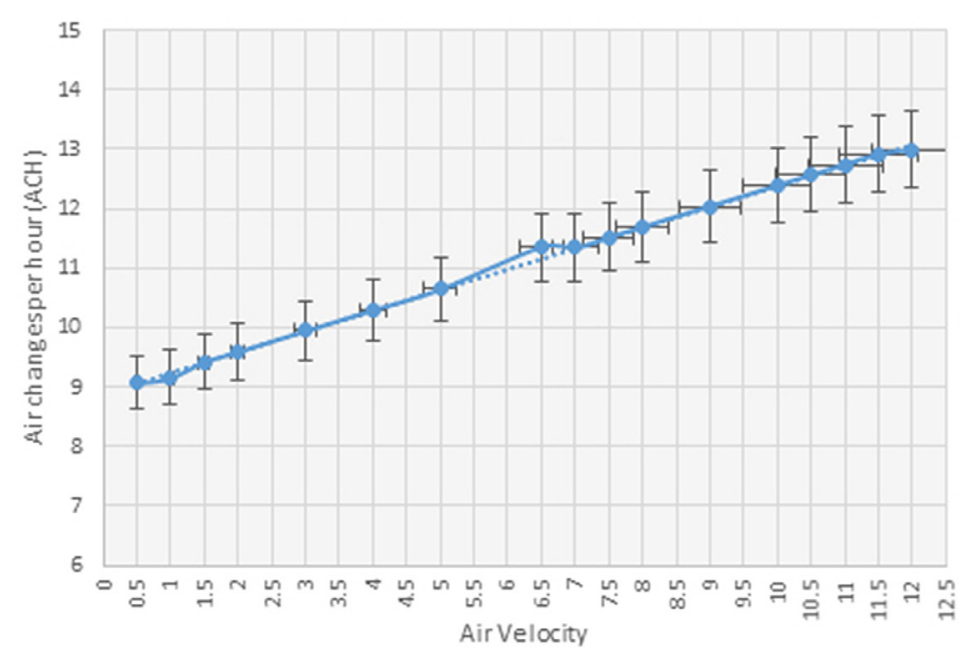

Figure 13. Air velocity and $\mathrm{ACH}$ 
exchange. The higher the external wind velocity, the higher the rate of air change. Figure 13 shows the simulation results covering different wind speeds and the resultant air exchange rate. Simulations reflect the capability of the optimized wind tower to exhaust the air to create a high quality and healthy ventilation system for a terminal.

\section{Evaporative cooling}

An evaporative cooling technique is used in the wind tower design for cooling the inlet air and providing thermal comfort in the interior. The design made of wetted pad at the bottom part of the tower, modeled as the surfaces that are injected with droplets of water at very low speed. When air passes over moist surfaces, it absorbs high amount of heat from the air, which results in the air temperature reduction.

The Honeybee (energy plus) definition for Grasshopper used to simulate and analyze the temperature values and distribution in the experimental room. Figure $14(\mathrm{a}+\mathrm{b})$ represents the hourly ambient temperatures for the experimental room during the period of study (1st March to 31 st October). The temperature values are visualized on the colored charts and represent two situations - hourly ambient temperatures without using the wind tower (Figure 14a) and hourly ambient temperatures with using the wind tower and the evaporative cooling device (Figure 14b).

The higher ambient temperatures in the experimental room reached $38^{\circ} \mathrm{C}$ without using the wind tower and the evaporative cooling device. The peak ambient temperature was obtained during the last week of July. There were $82 \%$ of daytime hours when the ambient temperatures were over $25^{\circ} \mathrm{C}$ and $18 \%$ daytime hours when the ambient temperatures were below $25^{\circ} \mathrm{C}$. With the use of the wind tower and the evaporative cooling device, about $52 \%$ of the daytime hours were over $25^{\circ} \mathrm{C}$ and $48 \%$ below $25^{\circ} \mathrm{C}$. The cooling device managed to decrease the inlet air temperature and resulted in average temperature difference of $6.164^{\circ} \mathrm{C}$ for the interior space.

\section{CONCLUSIONS}

The efficiency of the proposed wind-induced natural ventilation tower was analyzed using Autodesk CFD and Grasshopper environmental simulations in order to establish a suitable natural ventilation system for the train station in Aqaba, Jordan. This research shows that the designed natural ventilation tower has high application

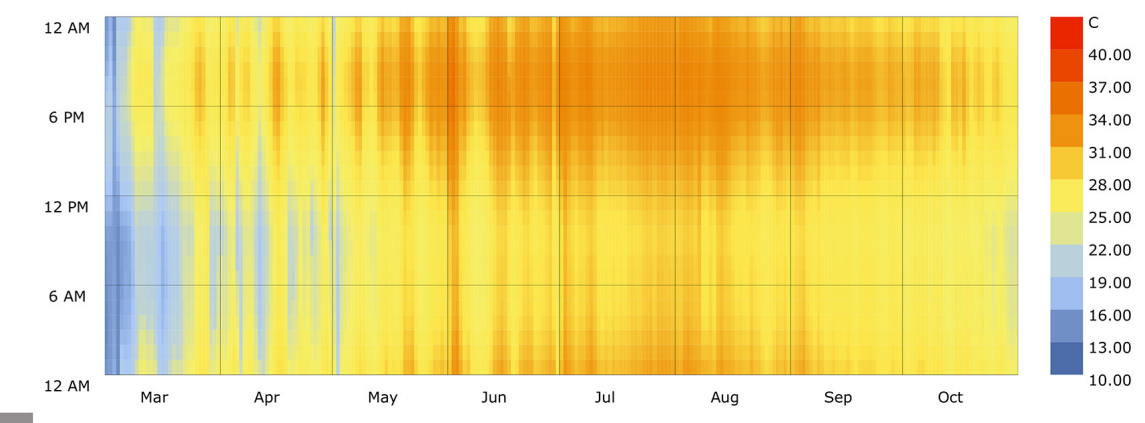

A

Temperature (C) - Hourly
WITHOUT TOWER
1 MAR $1: 00-31$ OCT $24: 00$ (a)

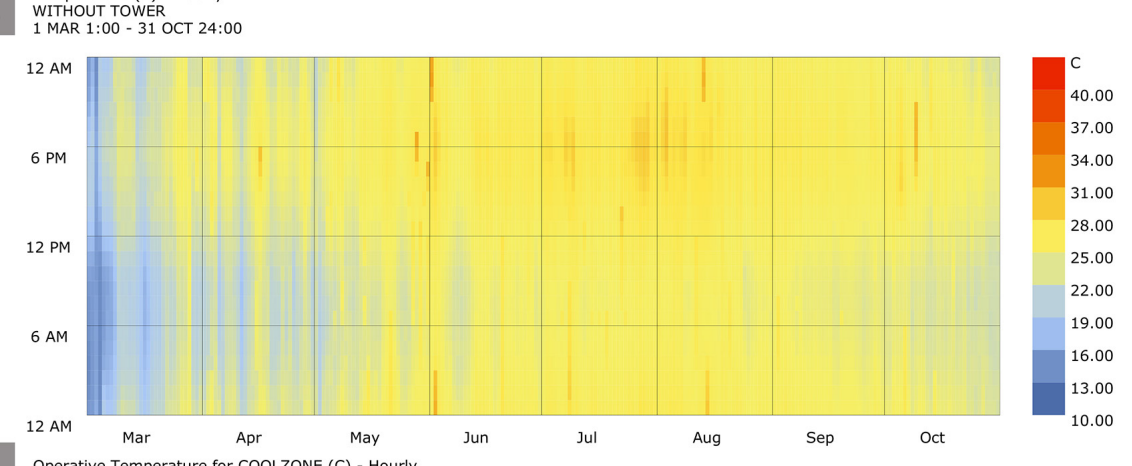

Operative Temperature for COOLZONE (C) - Hourly Aqaba Hussein Intl AP AQ JOR ISD-TMYX
1 MAR 1:00 - 31 OCT 24:00

Figure 14. (A) Hourly ambient temperatures without using the wind tower, (B) hourly ambient temperatures with using the wind tower and the evaporative cooling device 
potentials in buildings in hot and arid climates. It was observed that $60 \%$ of the site's wind speed is below $11 \mathrm{~m} / \mathrm{s}$. The wind-induced natural ventilation tower has demonstrated the potential to provide adequate airflow into interior spaces at an exterior air velocity of $6.5 \mathrm{~m} / \mathrm{s}$. The study showed that the optimized tower's aerodynamic efficiency in generating sufficient airflow and induce the fresh air from the outside into the experimental indoor environment. On the basis of the CFD simulations, the air exchange rate for the optimized tower was 11,355 . This ACH can be increased with the increase of the external wind speeds. The wind-induced natural ventilation tower is capable of providing air movement which enables passengers to feel fresh and comfortable, in compliance with ASHRAE standard 62.

The evaporative cooling results incorporating cooling pad at the lower parts of the tower showed the efficiency of the tower in reducing the inlet air temperature up to $6.164^{\circ} \mathrm{C}$, depending on the configuration of the experimental room. Another advantage of the proposed system is the reliance on the minimal supply of water in the cooling cycle.

\section{REFERENCES}

1. Abu-Ghazalah, S. 2008. The sustainable city development plan for Aqaba, Jordan. Journal of Developing Societies, 24(3), 381-398.

2. Alzoubi, H. H., \& Malkawi, A. T. 2011. Investigating the Effect of Building Orientation on Thermal Comfort and Energy consumption in Educational Buildings. Paper presented at the Global Conference on Renewable energy and Energy Efficiency for Desert Regions.

3. Aynsley, R. 2014. Natural ventilation in passive design. Environment Design Guide, 1-16.

4. Badran, A. A. 2003. Performance of cool towers under various climates in Jordan. Energy and Buildings, 35(10), 1031-1035.

5. Bahadori, M. N. 1985. An improved design of wind towers for natural ventilation and passive cooling. Solar Energy, 35(2), 119-129.

6. Billington, N. S., \& Roberts, B. M. 1982. Building services engineering: a review of its development: Pergamon Press Oxford.

7. Calautit, J. K., Hughes, B. R., \& Sofotasiou, P. 2015. Design and Optimisation of a Novel Passive Cooling Wind Tower.

8. Chenari, B., Carrilho, J. D., \& da Silva, M. G. 2016. Towards sustainable, energy-efficient and healthy ventilation strategies in buildings: A review.
Renewable and Sustainable Energy Reviews, 59, 1426-1447.

9. Drees, K. H., Wenger, J. D., \& Janu, G. 1992. Ventilation air flow measurement for ASHRAE Standard 62-1989. ASHRAE Journal (American Society of Heating, Refrigerating and Air-Conditioning Engineers);(United States), 34(10).

10. Fathy, H. 1986. Natural energy and vernacular architecture.

11. Ghadiri, M. H., Ibrahim, N. L. N., \& Dehnavi, M. 2011. The effect of tower height in square plan wind catcher on its thermal behavior. Australian Journal of Basic and Applied Sciences, 5(9), 381-385.

12. Ghiaus, C., \& Roulet, C.-A. 2005. Strategies for natural ventilation. Natural ventilation in the urban environment: Assessment and design, 136-157.

13. Gil-Baez, M., Barrios-Padura, Á., Molina-Huelva, M., \& Chacartegui, R. 2017. Natural ventilation systems in 21st-century for near zero energy school buildings. Energy, 137, 1186-1200.

14. Grondzik, W. T., \& Kwok, A. G. 2019. Mechanical and electrical equipment for buildings: John wiley $\&$ sons.

15. Haghighi, A., Golshaahi, S., \& Abdinejad, M. 2015. A study of vaulted roof assisted evaporative cooling channel for natural cooling of 1-floor buildings. Sustainable Cities and Society, 14, 89-98.

16. Haw, L. C., Saadatian, O., Sulaiman, M., Mat, S., \& Sopian, K. 2012. Empirical study of a wind-induced natural ventilation tower under hot and humid climatic conditions. Energy and Buildings, 52, 28-38.

17. Hughes, B. R., Calautit, J. K., \& Ghani, S. A. 2012. The development of commercial wind towers for natural ventilation: A review. Applied energy, 92, 606-627.

18. Jaber, J. O. 2002. Future energy consumption and greenhouse gas emissions in Jordanian industries. Applied energy, 71(1), 15-30.

19. Jiang, Y., Li, K., Tian, L., Piedrahita, R., Yun, X., Mansata, O., ... Shang, L. 2011. MAQS: a personalized mobile sensing system for indoor air quality monitoring. Paper presented at the Proceedings of the 13th international conference on Ubiquitous computing.

20. Jomehzadeh, F., Nejat, P., Calautit, J. K., Yusof, M. B. M., Zaki, S. A., Hughes, B. R., \& Yazid, M. N. A. W. M. 2017. A review on windcatcher for passive cooling and natural ventilation in buildings, Part 1: Indoor air quality and thermal comfort assessment. Renewable and Sustainable Energy Reviews, 70, 736-756.

21. Kalantar, V. 2009. Numerical simulation of cooling performance of wind tower (Baud-Geer) in hot and arid region. Renewable Energy, 34(1), 246-254.

22. Khan, N., Su, Y., \& Riffat, S. B. 2008. A review 
on wind driven ventilation techniques. Energy and Buildings, 40(8), 1586-1604.

23. Li, J., Delmas, A., Donn, M., \& Willis, R. 2018. Validation and comparison of different CFD simulation software predictions of urban wind environment based on AIJ wind tunnel benchmarks. Paper presented at the Proceedings of the Symposium on Simulation for Architecture and Urban Design.

24. Lim, C. H., Saadatian, O., Sulaiman, M. Y., Mat, S., \& Sopian, K. 2012. Air Changes and Extraction Flow Rate Analysis of Wind-Induced Natural Ventilation Tower under hot and humid climatic conditions. Paper presented at the IEEE Business, Eng. Ind. Appl. Colloq.

25. Montazeri, H. 2011. Experimental and numerical study on natural ventilation performance of various multi-opening wind catchers. Building and Environment, 46(2), 370-378.

26. Montazeri, H., \& Azizian, R. 2008. Experimental study on natural ventilation performance of onesided wind catcher. Building and Environment, 43(12), 2193-2202.

27. Montazeri, H., \& Montazeri, F. 2018. CFD simulation of cross-ventilation in buildings using rooftop wind-catchers: Impact of outlet openings. Renewable Energy, 118, 502-520.

28. Oliver, P. 1997. Encyclopedia of vernacular architecture of the world (Vol. 3): Cambridge University Press Cambridge.
29. Omer, A. M. 2008. Renewable building energy systems and passive human comfort solutions. Renewable and Sustainable Energy Reviews, 12(6), 1562-1587.

30. Papadopoulos, A., \& Avgelis, A. 2003. Indoor environmental quality in naturally ventilated office buildings and its impact on their energy performance. International Journal of Ventilation, 2(3), 203-212.

31. Pearlmutter, D., Erell, E., Etzion, Y., Meir, I., \& Di, H. 1996. Refining the use of evaporation in an experimental down-draft cool tower. Energy and Buildings, 23(3), 191-197.

32. Roudsari, M. S., Pak, M., \& Smith, A. 2013. Ladybug: a parametric environmental plugin for grasshopper to help designers create an environmentally-conscious design. Paper presented at the Proceedings of the 13th international IBPSA conference held in Lyon, France Aug.

33. Sherman, M. H. 2004. ASHRAE's first residential ventilation standard. Proc. Buildings.

34. Yu, Y., You, S., Zhang, H., Ye, T., Zheng, X., \& Wang, Y. 2019. Review of Passive Strategies for Ventilation and Air-Conditioning Energy Saving in Underground Metro Stations.

35. Zaki, A., Richards, P., \& Sharma, R. 2019. Analysis of airflow inside a two-sided wind catcher building. Journal of Wind Engineering and Industrial Aerodynamics, 190, 71-82. 